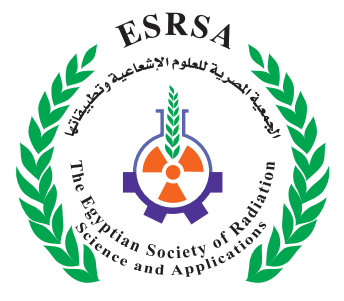

J. Nucl. Tech. Appl. Sci., Vol. 9, PP. 47 : 52 (2021)

\title{
Background Radiation Survey at Major Dumpsites in Freetown, Sierra Leone
}

Kamara, A.J. ${ }^{1 *}$ and Thullah, F. ${ }^{2}$

Received: 09/05/2021

Accepted: 28/07/2021

DOI: $10.21608 /$ jntas.2021.75841.1038

E.mail:chieftonyit1983@gmail.com

\section{KEYWORDS}

Dose rate, Dumpsites, Exposure, Radiation, Scavenger.

\section{ABSTRACT}

Dumpsites in Freetown the capital city of Sierra Leone have become major areas for urban agriculture. Moreover, many youths in communities around dumpsites scavenge various materials including scrap metals and sachet plastics from the dumpsites on a daily basis for survival. The two notable dumpsites, Kingtom and Granville Brooke dumpsites are open dumpsites that accommodate all types of mixed solid wastes some of which may emit or have the potential to emit radiation. In-situ measurement of the radiation dose rate was conducted on the two sites using a portable Radiagem survey meter and a Geographical Positioning System (GPS). Ten (10) measurements were made for each dumpsite. The result of the radiation measurements showed that the mean equivalent dose rate for the Kingtom and Granville Brooke dumpsites are $0.8 \mathrm{mSvy}^{-1}$ and 1.1 $\mathrm{mSvy}^{-1}$ respectively. These values revealed that the Kingtom dumpsite has slightly higher value than the permissible limits of United Nations Scientific Committee on the Effect of Atomic Radiation (UNSCEAR) and lower than the permissible limits of International Commission on Radiological Protection (ICRP); whereas for the Granville Brooke dumpsite the mean equivalent dose rate is higher than both the permissible limits set by UNSCEAR and ICRP. It is therefore justifiable to conclude

1. Department of Physics, Fourah Bay College, University of Sierra Leone.

2. Department of Chemistry, Fourah Bay College, University of Sierra Leone. 
that both dumpsites, Kingtom and Granville Brooke could be unsafe in the near future from the cumulative effect of radiation exposure for workers, scavengers and other individuals exposed to loads of wastes in the dumpsites.

\section{.INTRODUCTION}

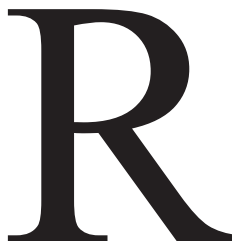

adiation is the emission or transmission of energy in the form of waves or particles through space or through a material medium. It exists in two (2) forms: ionizing and non-ionizing radiations (Temaugee et al., 2014). Ionizing radiation can produce charged particles (ions) in matter and is formed by unstable atoms which have an excess of energy or mass or both (Gani and Okojie, 2013). Non-ionizing radiations include light, radio, and microwave. Every individual is exposed to radiation of one kind or another. Cosmic rays and naturally occurring radioactive substances present in the earth's crust and human body are natural sources of radiation (De-Rong et al., 2015). A common source of ionizing radiation is radioactive materials that emit alpha $(\alpha)$, beta $(\beta)$, or gamma $(\gamma)$ radiation e.g. radon, from rocks and soils. Other sources include medical devices, including X-ray machines and Xray fluorescence (XRF) machines used in industry and research. Mesons and other particles constitute the secondary cosmic rays that are produced after primary cosmic rays interact with earth's atmosphere (IAEA, 2011). Radionuclides can be found in different rock types propagated around our environment, with little addition from cosmic rays (cosmogenic). Radionuclides present in rocks, air, food and water, form part of the Naturally Occurring Radioactive Material (NORM) in the environment, which when not properly audited and controlled, are capable of emitting mixed radiation to the environment (Usikalu et al., 2017).

Ionizing radiation has many beneficial applications, including uses in medicine, industry, agricul- ture and research. As the use of ionizing radiation increases, so does the potential for health hazards if not properly used or contained. Acute health effects such as skin burns or acute radiation syndrome can occur when doses of radiation exceed certain levels. Low doses of ionizing radiation can increase the risk of longer-term effects such as cancer. Beyond certain thresholds, radiation can impair the functioning of tissues and/or organs and can produce acute effects such as skin redness, hair loss, radiation burns, or acute radiation syndrome. These effects are more severe at higher doses and higher dose rates (about $1 \mathrm{~Sv})$. Exposure to radiation has been linked with most forms of leukemia and cancers in organs such as lungs, breasts and thyroid glands (Borek, 2004; UNSCEAR, 2017).

Municipal wastes, including domestic, agricultural, electronic, medical and industrial wastes (food wastes, paper, polyethene, textiles, scrap metals, glass, wood, plastic, insecticides containers, fluorescence light bulbs, paints etc.) are deposited at various dumpsites around the city. Some of the wastes may serve as common sources of ionizing radiation (Avwiri and Olatubosun, 2014; Ugochukwu et al., 2015). Constituents of the dumpsites such as medical devices, and other radionuclide-containing substances may cause public nuisance and also serve as a source of radiation due to the accumulation of radionuclides (Olubosede et al., 2012). Dumpsite workers, scavengers and inhabitants residing in and around the dumpsites may be exposed to different doses of radiation that can lead to health problems such as highlighted above (Sigalo and Briggs-Kamara, 2004). Natural levels of background ionizing radiation is generally between 0.7 to $1.0 \mathrm{mSv} \mathrm{yr}^{-1}$ (ICRP, 2007; UNSCEAR, 2017).

The Kingtom and Granville Brooke dumpsites are open dumpsites because all categories of wastes are dumped in (domestic, hospital, electronics, agricultural, industrial, etc). The Kingtom dumpsite is surrounded by a cemetery (left side), a market (at the 
front and back sides) and a residential area (front, back and right sides). A river runs at the back of the dumpsite (Congo Town River) and empties into the sea. The Granville Brooke dumpsite is surrounded by factories (right and back sides), an established community (back and left sides) and a highway that runs to the central business area of the capital. The Granville Brooke River runs through the dumpsite and empties into the big sea (Frazer-Williams, 2015). Communities from the Kingtom and Granville Brooke dumpsites face a lot of health hazards emanating from the dumpsites. During the raining season, leaches from the dumpsite run into borehole and stream waters used by the community for domestic and drinking purposes; insecticides and scavengers run into households; and heavy wind blows debris into communities. During the dry season, smokes and heat emanating from the dumpsites pollute the environment thereby causing respiratory diseases and breathing disorders; also thick smokes covering the highway results in accidents (Akpan and Olukanni, 2020). As a result of the potential health hazard that emanate from dumpsites, this research was designed to investigate levels of radiation at the two notable dumpsites in Freetown in order to ascertain potential radioisotope exposure.

\section{MATERIAL AND METHOD}

Kingtom and Granville Brooke dumpsites are two (2) notable dumpsites that have existed for decades in Freetown, the capital city of Sierra Leone. The Kingtom dumpsite is situated at the West end of Freetown with coordinates $06^{\circ} 92.949^{\prime} \mathrm{N}$ and $09^{\circ} 38.436^{\prime} \mathrm{E}$ and Granville Brooke dumpsite is situated at the East end of Freetown with coordinates $06^{\circ} 97.151^{\prime} \mathrm{N}$ and $09^{\circ} 37.964^{\prime} \mathrm{E}$. Figure 1.0 and Figure 2.0 gives a map of the study area. These dumpsites are open dumpsites that serve as repositories of all categories of wastes (domestic, electronic, medical, agricultural, industrial wastes etc.) (Frazer-Williams, 2015; Thullah et al., 2019). In-situ method of measurement of radioactivity dose was carried out at the two (2) dumpsites using a portable RADIAGEM $^{\mathrm{TH}} 2000$ survey meter and the results obtained are shown in tables 1.0 and 2.0 for Kingtom and Granville Brooke dumpsites respectively. This type of survey meter is suitable for field measurements due to its fast response and capability to locate the hot spots. The RADIAGEM ${ }^{\mathrm{TH}} 2000$ survey meter is an energy-compensated Geiger-Muller counter in the gamma energy range from $40 \mathrm{keV}$ to $1.5 \mathrm{MeV}$ with an approximate accuracy of $25 \%$ and operated with two (2) 1.5 Volt batteries. The detector has high sensitivity to measure low levels of alpha (down to 2 $\mathrm{MeV}$ ), beta (down to $0.16 \mathrm{MeV}$ ) and gamma (down to $10 \mathrm{keV}$ ) radiation through the end window.

At each of the two dumpsites selected, measurements were made randomly at ten (10) different points at about $5 \mathrm{~m}$ apart and the survey meter was held at the gonald level (about 1 meter above ground level) for effective detection. During measurement the meter was switched on to absorb radiation for few seconds and stable reading recorded. The procedure was repeated at each location and readings were recorded in micro Sievert per hour $\mu \mathrm{Sv} / \mathrm{hr}$. The mean values were obtained from the data collected.

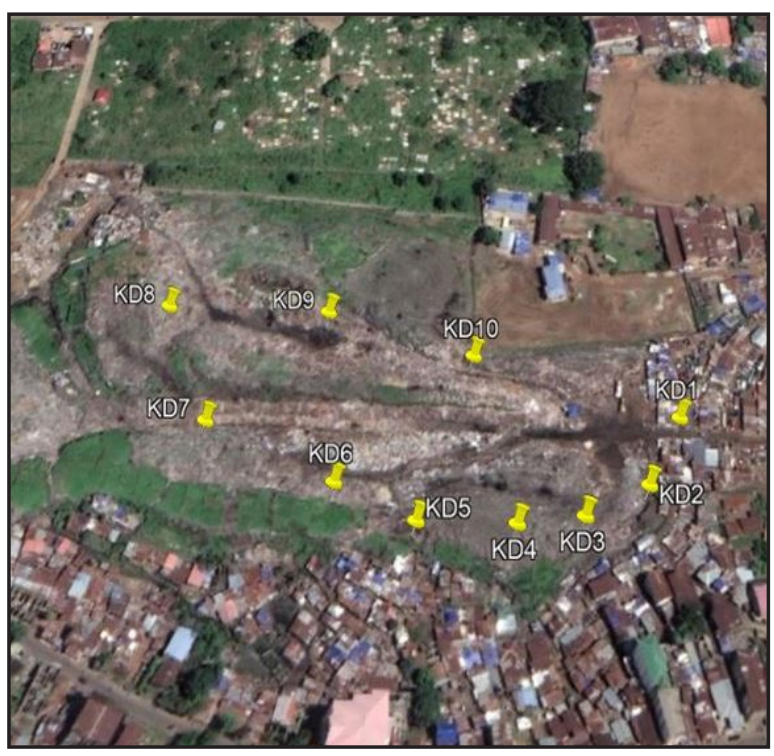

Fig. (1): Kingtom Dumpsite. 


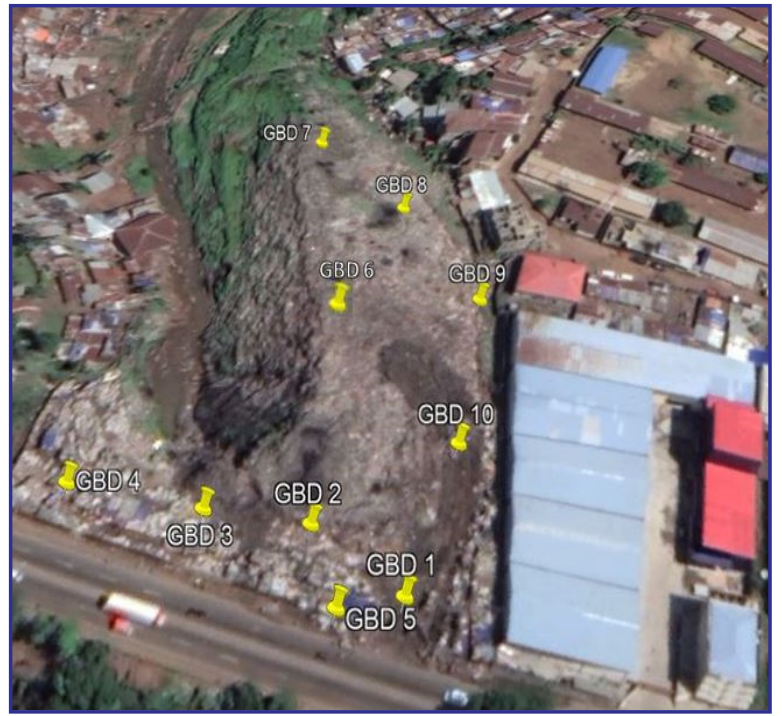

Fig. (2): Granville Brooke Dumpsite.

\section{RESULTS}

The results of the radiation dose rate survey and annual equivalent dose rate for ten (10) different points at each dumpsite and the corresponding Global Positioning System (GPS) coordinates are recorded in Tables 1.0 and 2.0 respectively.

\section{DISCUSSIONS}

The background radiation measured from the Kingtom and Granville Brooke dumpsites range from $0.05 \mu \mathrm{Sv} / \mathrm{hr}$ to $0.12 \mu \mathrm{Sv} / \mathrm{hr}$ and $0.06 \mu \mathrm{Sv} / \mathrm{hr}$ to $0.2 \mu \mathrm{Sv} / \mathrm{hr}$ respectively. The High radiation dose readings observed at these dumpsites could be due to the different types of waste deposited especially; domestic, agricultural, industrial, hospitals, scrap metals and electronic wastes (some of which may be radionuclide-containing substances). The background radiation exposure rate obtained in this research are higher than the global background radiation standard of $0.02 \mu \mathrm{Sv} / \mathrm{hr}$ (UNSCEAR, 2017). The annual equivalent dose rate was estimated using the expression (UNSCEAR, 1998)

$$
\mu \mathrm{Svh}^{-1}=8.766 \mathrm{mSvy}^{-1}
$$

The mean annual equivalent dose rate values obtained from Kingtom dumpsite reveals that it is slightly higher than the permissible limit of 0.7 $\mathrm{mSvy}^{-1}$ according to UNSCEAR-2000 and lower than the permissible limit of $1.0 \mathrm{mSvy}^{-1}$ for ICRP2009. Also, for the Granville Brooke dumpsite, the mean annual equivalent dose rate value reveals that it is higher than the permissible limit of $0.7 \mathrm{mSvy}^{-1}$ for UNSCEAR - 2000 and slightly higher than the permissible limit of $1.0 \mathrm{mSvy}^{-1}$ for ICRP- 2009. In Sierra Leone, there has never been any research conducted on radiation monitoring of dumpsites but similar studies have been conducted within West Africa. Results obtained from this research can be compared with results obtain from Port Harcourt, River State, Nigeria (Avwiri and Olatubosun, 2014). In-situ measurement of the highest average equivalent dose rate in this study was higher than that from Port Harcourt $(1.592 \pm 0.239 \mathrm{mSv} / \mathrm{yr})$. Figure 3.0 shows the in-situ average equivalent dose rate for each dumpsite compared with ICRP and UNSCEAR threshold (ICRP, 2007; UNSCEAR, 2017). From figure 3 the mean equivalent dose rate value for Granville Brook dumpsite is higher than that for Kingtom dumpsite. Both Kingtom and Granville Brooke dumpsites were established as open dumpsites in Freetown several decades ago, with Kingtom dumpsite being the first to be established. However, most industries are located in the East-end of Freetown (Oil refinery, Cement factory, Milla group Ltd., Shankerndas and Sons Ltd, Soap factory, Brewery etc.). Invariably, wastes (some of which may be radionuclide-containing substances) from all these industries end up at the Granville Brooke dumpsite. This may explain in part, why Granville Brooke dumpsite show higher mean annual equivalent dose rate values than the Kingtom dumpsite in the west-end of Freetown. 
Table (1) : Radiation dose results for Kingtom dumpsite.

\begin{tabular}{|c|c|c|c|c|}
\hline \multirow{2}{*}{ Sample Id } & \multirow{2}{*}{$\begin{array}{c}\text { Dose Rate }(\boldsymbol{\mu S v} / \\
\mathbf{h r})\end{array}$} & \multirow{2}{*}{$\begin{array}{c}\text { Dose Rate } \\
(\mathbf{m S v} / \mathbf{y})\end{array}$} & \multicolumn{2}{|c|}{ Coordinates } \\
\cline { 4 - 5 } & 0.11 & 1.0 & 693031 & Longitude $\left({ }^{\mathbf{}} \mathbf{E}\right)$ \\
\hline KD 1 & 0.09 & 0.8 & 693013 & 938431 \\
\hline KD 2 & 0.12 & 1.1 & 692981 & 938398 \\
\hline KD 3 & 0.10 & 0.9 & 692949 & 938378 \\
\hline KD 4 & 0.11 & 1.0 & 692902 & 938380 \\
\hline KD 5 & 0.08 & 0.7 & 692863 & 938399 \\
\hline KD 6 & 0.09 & 0.8 & 692799 & 938430 \\
\hline KD 7 & 0.06 & 0.5 & 692776 & 938489 \\
\hline KD 8 & 0.07 & 0.6 & 692858 & 938484 \\
\hline KD 9 & 0.10 & 0.9 & 692931 & 938461 \\
\hline KD 10 & & & \\
\hline
\end{tabular}

Table (2) : Radiation dose results for Granville Brooke dumpsite.

\begin{tabular}{|c|c|c|c|c|}
\hline \multirow{2}{*}{ Sample Id } & \multirow{2}{*}{$\begin{array}{c}\text { Dose Rate }(\boldsymbol{\mu S \mathrm { Sv }} / \\
\mathbf{h r})\end{array}$} & \multirow{2}{*}{$\begin{array}{c}\text { Dose Rate } \\
(\mathbf{m S v} / \mathbf{y})\end{array}$} & \multicolumn{2}{|c|}{ Coordinates } \\
\cline { 4 - 5 } & 0.13 & 1.1 & 697145 & Latitude $\left({ }^{\mathbf{}} \mathbf{N}\right)$ \\
\hline GBD 1 & 0.06 & 0.5 & 697122 & 937912 \\
\hline GBD 2 & 0.09 & 0.8 & 697095 & 937929 \\
\hline GBD 3 & 0.11 & 1.0 & 697060 & 937933 \\
\hline GBD 4 & 0.17 & 1.5 & 697129 & 937939 \\
\hline GBD 5 & 0.06 & 0.5 & 697121 & 937013 \\
\hline GBD 6 & 0.27 & 2.4 & 697117 & 938070 \\
\hline GBD 7 & 0.10 & 0.9 & 697145 & 938040 \\
\hline GBD 8 & 0.09 & 0.8 & 697167 & 937997 \\
\hline GBD 9 & 0.14 & 1.2 & 697159 & 937950 \\
\hline GBD 10 & & & & \\
\hline
\end{tabular}

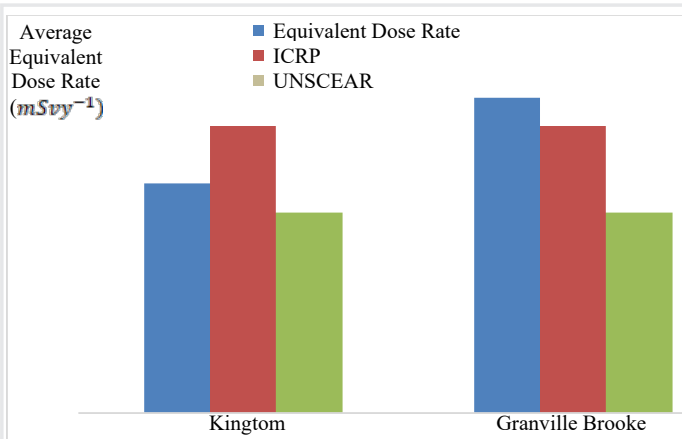

Fig. (3): Equivalent dose rate obtained from studies compared with ICRP (1990) and UNSCEAR (2000) Threshold.

\section{CONCLUSION AND RECOMMENDATIONS}

The high radiation values obtained in this research suggest the presence of radionuclides in the dumpsites which could possibly be from municipal, domestic, medical, electronic, agricultural and industrial wastes randomly deposited in the dumpsites. High radiation at the two sites poses potential radiation risk to humans, plants and animals health in the environment. Emitted radiation from dumpsites may 
also affect surface water, soil and underground water sources in the environment through leaching and seepage; as well as precipitation of radionuclides from the atmosphere. However, the following can be considered for future work:

- regular and periodic monitoring of ionizing radiation levels in all dumpsites in Freetown and its environs.

- urgent attention and appropriate response be made for the safety of the environment and health impacts on workers, scavengers and inhabitants in and around the dumpsites.

- further research is recommended regarding the composition of dumpsites to ascertain levels of radiological impact on workers at dumpsite communities and environment.

the two dumpsites be relocated to areas well outside the city and its environs

\section{REFERENCES}

- Akpan, V.E. and Olukanni, D.O. (2020): Hazardous Waste Management: An African Overview. Recycling 5: 15 .

- Avwiri, G.O. and Olatubosun, S.A. (2014): Assessment of Environmental Radioactivity In Selected Dumpsites In Port Harcourt, Rivers State, Nigeria. Int. J. Sci. Res., 3: 263.

- Borek, C. (2004): Antioxidants and Radiation. Therapy. J. Nut., 134: 3207.

- De-Rong, X.; Hong-Liang, X. and Yan, S. (2015): Producing terahertz coherent synchrotron radiation at the Hefei Light Source. Chinese Phys., 39.

- Frazer-Williams, R.A.D. (2015): Risk Assessment of The Kingtom And Granville Brook Dumpsites In Freetown, Sierra Leone. Niger. J. Pharm. Sci., 4: 10.

- Gani, O.I.O. and Okojie, O.H. (2013): Environmental audit of a refuse dump site in the Niger Delta re- gion of Nigeria. J. Public Health Epidemiol., 5: 59.

- IAEA (2011): International Atomic Energy Agency. Annual Report.

- ICRP (2007): Report on the International Commission on Radiological Protection Publication.

- Olubosede, O.; Akinagbe, O.B. and Adekoya, O. (2012): Assessment of Radiation Emission from waste Dumpsites in Lagos State of Nigeria. Int. J. Comput. Eng. Sci., 2(3): 806.

- Sigalo, F.B. and Briggs-Kamara, M.A. (2004): Estimates of ionizing radiation levels within selected rivierine communities of the niger delta. J. Nigerian Environ. Soc., 2: 159.

- Temaugee, S.T.; Daniel, T.A.; Oladejo, K.O. and Daniel, S. (2014): Assessment of Public Awareness of the Detrimental Effects of Ionizing Radiation in Kontagora, Niger State, Nigeria. Int. J. Adv. Sci. Technol., 4: 2224.

- Thullah, F.; Kamara, A.J. and Kamara, M. (2019): Comparative studies of metal ( $\mathrm{Pb}, \mathrm{Cr}, \mathrm{Hg}, \mathrm{As}$ and $\mathrm{Al})$ uptake by leafy vegetables and fruit grown in gardens around the king tom refuse dump in Freetown. Asian J. Inf. Technol., 10: 9751.

- Ugochukwu, K.O.; Ijeoma, D.; Chidiezie, C.; Christiana, G. and Chiamaka, C. (2015): Characterization of Radiation Exposure Dose Rate from Waste Dumpsites within Owerri, Nigeria: An Atmospheric Concern. British J. Appl. Sci. Technol., 11: 1.

- UNSCEAR (2017): Report of the United Nations Scientific Committee on effects of Atomic Radiation Sources and effects of Ionizing Radiation.

- UNSCEA (1998): Exposure from Natural Radiation Sources. United Nations Scientific Committee on effects of Atomic Radiation Report.

- Usikalu, M.R.; Ola, O.O.; Achuka, J.A.; Babarimisa, I.O. and Ayara, W.A. (2017): Background radiation dose of dumpsites in Ota and Environs. J. Phy. Conf. Series, 852: 012045. 